\title{
ARTIGOS
}

Submetido 27.01.2020. Aprovado 22.06.2020

Avaliado pelo sistema double blind review. Editora científica convidada: Juliana Teixeira

Versão original | DOI: http://dx.doi.org/10.1590/So034-759020210402

\section{MEMÓRIAS EM MOVIMENTO: HISTÓRIAS DA CASA TINA MARTINS NO COMBATE À VIOLÊNCIA DE GÊNERO}

\author{
Moving memories: Stories of the Tina Martins shelter in the fight against gender violence \\ Recuerdos en Movimiento: Historias de la Casa Tina Martins en la lucha contra la violencia de género
}

Thaís Zimovski Garcia de Oliveira ${ }^{1}$ | thais.zimovski@yahoo.com.br | 0000-0003-1130-0810 Rafael Diogo Pereira² | rdpereira@face.ufmg.br | ORCID: 0000-0002-1057-2614 Alexandre de Pádua Carrieri ${ }^{1}$ | alexandre@face.ufmg.br | ORCID: 0000-0001-8552-8717 Gabriel Farias Alves Correia ${ }^{1}$ | correiagfa@gmail.com | ORCID: 0000-0002-8534-0543

1 Universidade Federal de Minas Gerais, Centro de Pós-Graduação e Pesquisas em Administração, Belo Horizonte, Minas Gerais, Brasil

2 Universidade Federal de Minas Gerais, Departamento de Ciências Administrativas, Belo Horizonte, Minas Gerais, Brasil

\section{RESUMO}

O objetivo deste artigo é apresentar as diversas histórias e memórias da Casa de Referência da Mulher Tina Martins. Para isso, partiu-se dos estudos qualitativos sobre história e memória nos Estudos Organizacionais baseados na virada histórica (historic turn), a qual visa ir além da produção de narrativas que utilizam o passado como ferramenta de reprodução das relações de poder do presente. Por meio de uma observação participante, foi construído um vasto material, como um caderno de campo, registros de eventos, fotografias e entrevistas individuais gravadas e transcritas. Esses resultados foram organizados em dois percursos temáticos principais: primeiro, apresentou-se o processo de criação da Casa, envolvendo as disputas políticas pelo seu espaço. Em seguida, foram trabalhados os sentidos presentes no cotidiano do grupo. Tendo em vista a construção de narrativas históricas diversificadas e processuais, foram propostas algumas reflexões críticas sobre a experiência da Casa, discutidas junto às integrantes, instigando, por meio das memórias, trabalhos históricos no campo dos Estudos Organizacionais.

PALAVRAS-CHAVE | Memórias, violência de gênero, movimento social, Casa Tina Martins, História.

\section{ABSTRACT}

This article presents different stories and memories of the Tina Martins Women's Referral Center. To this end, we moved away from the qualitative studies of history and memory in organizational studies that are based on the historic turn, which aims to go beyond the production of narratives that resort to the past as a tool for reproducing the power relations of the present. A vast amount of material was compiled from observing participants, including a field notebook, event records, and photographs, and individual interviews were recorded and transcribed. The results were organized into two main thematic axes: the first presents the process that led to the Center's foundation and the political disputes over its space, while the second addresses the meanings present in the group's everyday life. Given the construction of diversified and procedural historical narratives, this article proposes some critical reflections on the Center's experience that were discussed with its members, and instigates, via memories, the adoption of the historical approach to organizational studies.

KEYWORDS I Memory, gender violence, social movements, Casa Tina Martins, History.

\section{RESUMEN}

Este artículo tiene como objetivo presentar las diversas historias y recuerdos de la Casa de Referencia de la Mujer Tina Martins. Para ello, se partió de los estudios cualitativos sobre historia y memoria en los Estudios Organizacionales basados en el giro histórico (historic turn), cuyo objetivo es ir más allá de la producción de narrativas que utilizan el pasado como herramienta para reproducir las relaciones de poder del presente. A través de una observación participante, se construyó un vasto material, como un cuaderno de campo, registros de eventos, fotografías y entrevistas individuales grabadas y transcritas. Estos resultados se organizaron en dos caminos temáticos principales: primero, se presentó el proceso de creación de la Casa. Luego, se abordaron los sentidos presentes en la vida diaria del grupo. Como conclusión, se propusieron algunas reflexiones críticas sobre la experiencia de la Casa, discutidas con las mujeres del grupo, promoviendo a través de recuerdos trabajos históricos en el campo de los Estudios Organizacionales.

PALABRAS CLAVE I Recuerdos, violencia de género, movimiento social, Casa Tina Martins, Historia. 


\section{INTRODUÇÃO}

O Mapa da Violência (Waiselfisz, 2015) e o Projeto Gênero e Política na América do Sul (Corrêa \& Kalil, 2020) mostram a persistência da violência de gênero no Brasil. Trata-se de um fenômeno complexo que se ramifica por diferentes campos da vida cotidiana e apresenta desafios próprios a cada camada social (Narvaz \& Koller, 2006; Segato, 2003). Não se pode perder de vista que, apesar de alguns avanços conquistados pelas lutas das mulheres, como a criação de políticas públicas e leis federais como a Lei Maria da Penha (Lei no 11.340), muitos retrocessos ainda são enfrentados, especialmente pelas mulheres não brancas, com o aumento crítico da quantidade dos feminicídios no País (Waiselfisz, 2015).

Nesse contexto, foi criada a Casa de Referência da Mulher Tina Martins, em 2016, pelo movimento feminista Olga Benário, com a ocupação do refeitório do antigo prédio da Faculdade de Engenharia da Universidade Federal de Minas Gerais (UFMG). Sua trajetória iniciou-se em um tenso período de 87 dias de negociação com o governo do estado e culminou na conquista temporária de um imóvel tombado na região central de Belo Horizonte, sendo sustentada e mantida pelas próprias mulheres do movimento social.

Atualmente, o projeto é integrado à Rede Estadual de Enfrentamento à Violência contra a Mulher de Minas Gerais, ao lado de outras instituições e órgãos do governo, como o Centro de Apoio à Mulher Benvinda e o Núcleo de Defesa dos Direitos da Mulher em situação de Violência (Nudem). Uma vez que a rede se mobiliza para suprir as lacunas deixadas pelo governo nas cidades do interior, parte dos casos críticos é encaminhada à Casa, que, apesar de estar situada na capital, representa um espaço relevante de atuação em todo o estado. Vale notar que Minas Gerais teve uma taxa de feminicídio acima da média nacional, atingindo 1,3 ocorrência a cada 100 mil mulheres, remontando a um total de 136 casos no ano de 2019 (Velasco, Caesar, \& Reis, 2020).

Com este artigo, buscou-se apresentar as diversas histórias e memórias dessa experiência a partir de relatos de mulheres que participaram do projeto desde sua concepção até o momento presente. Para isso, partiu-se dos estudos qualitativos sobre história e memória nos Estudos Organizacionais baseados na virada histórica (historic turn), a qual visa ir além da produção de narrativas que utilizem o passado como ferramenta de reprodução das relações de poder do presente (Godfrey, Hassard, O’Connor, Rowlinson, \& Ruef, 2016). Por meio de uma observação participante, foi construído um vasto material, como um caderno de campo, registros de eventos, fotografias e entrevistas individuais. Esses resultados foram organizados de modo a elaborar narrativas históricas diversificadas e processuais capazes de abordar a complexidade dos sentidos produzidos pelo grupo no decorrer de sua trajetória.

As escolhas metodológicas serão tratadas em maior profundidade adiante, na terceira seção do trabalho, após uma discussão teórica sobre os temas que abordam a proposta deste artigo, a perspectiva histórica e as memórias na administração e a violência de gênero. Em uma visão geral, buscou-se, com a imersão no grupo, a possibilidade de tensionar a aparente dicotomia entre teoria e prática nas ciências, especialmente na Administração (Carrieri, Perdigão, Martins, \& Aguiar, 2018; Gabriel \& Carr, 2002). Nesse sentido, a pesquisa caminha para a apresentação dos resultados, tanto sobre a prática das mulheres no contexto de um movimento social contra a violência de gênero quanto sobre a consideração de suas memórias como fonte material na construção do conhecimento acadêmico no campo das organizações. Com isso, fomentam-se discussões na área de Estudos Organizacionais que se voltam para os sujeitos menores, do ponto de vista histórico, delineando que a temática das memórias possibilita acessar diversos saberes e historicizar diferentes modos de resistir das e nas organizações sociais. 


\section{A PERSPECTIVA HISTÓRICA E AS MEMÓRIAS NA ADMINISTRAÇÃO}

Diversos autores recentes buscaram discutir as contribuições da perspectiva histórica e das memórias para os Estudos Organizacionais. Destacam-se aqui os trabalhos de Clark e Rowlinson (2004), Costa, Barros e Martins (2010), Rowlinson, Booth, Clark, Delahaye e Procter (2010), Vizeu (2010), Souza e Costa (2013), Barros e Carrieri (2015), Maclean, Harvey e Clegg (2016), Coraiola, Foster e Suddaby (2017), Carrieri et al. (2018), Costa e Silva (2019), Carrieri e Correia (2020) e Decker, Rowlinson e Hassard (2020). Todos eles possuem em comum a discussão sobre os avanços e as possibilidades que a temática interdisciplinar oferece, apresentando caminhos alternativos para superar a concentração de estudos da Administração que buscam sobrelevar grandes histórias, sujeitos e narrativas.

A discussão recente que sinaliza o aumento de estudos na Administração a partir da ótica histórica foi sinalizada em Clark e Rowlinson (2004), sublinhando as produções com base nas discussões da virada histórica (historic turn). Em complemento, Vizeu (2010) coloca que esses estudos estão associados às renovações metodológicas e epistemológicas das ciências sociais que transcorreram na segunda metade do século XX, relacionadas aos questionamentos de práticas e discursos provenientes da academia.

A influência da perspectiva histórica possibilitou, segundo Clark e Rowlinson (2004), o questionamento de variáveis “simples" e do "cientificismo" nos estudos da Administração. Desse modo, é na virada histórica que as possibilidades de estudo se abrem no campo para novas ferramentas metodológicas, novos objetos de investigação, novas visões sobre os acontecimentos passados, além das próprias reflexões sobre as narrativas históricas e o papel da História a partir da ideia do passado como processo e contexto (Costa et al., 2010). É nesse movimento também que são sublinhadas as importâncias dos sujeitos menores, dos pequenos acontecimentos, das pequenas narrativas, das práticas e dos saberes promovidos por sujeitos desconsiderados no processo de criação do conhecimento (Barros \& Carrieri, 2015; Carrieri et al., 2018; Joaquim \& Carrieri, 2018).

Discussões recentes como as de Joaquim e Carrieri (2018), Wanderley e Barros (2018), Costa e Silva (2019) e Carrieri e Correia (2020) fomentam as contribuições históricas para os Estudos Organizacionais, e, com isso, destacam saberes geograficamente localizados e distanciados dos considerados grandes centros. Nesse sentido, os autores instigam os pesquisadores nacionais na busca pela superação do caráter a-histórico da Administração, incentivando a diminuição da dependência dos estudos estrangeiros nas reflexões sobre o tema. É a partir dessa linha de raciocínio que se pode justificar estudos históricos sobre organizações não empresariais na área, tendo em vista que a própria escolha por esse objeto de investigação já se apresenta como um olhar excluído das principais investigações. Costa e Silva (2019) ainda complementam que poucos são os trabalhos que se debruçam sobre o método histórico na Administração, afirmando a real necessidade de avanço nas particularidades e nos procedimentos aplicados à área, integrando fontes documentais, relatos históricos oficiais e histórias orais.

Já no campo das memórias, os objetos de estudo desvelam uma diversidade de temas e reflexões. A memória, seja ela individual ou coletiva, não é um simples repositório passivo de fatos, pelo contrário, se caracteriza como produto cultural imensurável (Guarinello, 2004). Essa mesma posição é adotada por Neves (2010) e Joaquim e Carrieri (2018) quando reforçam o caráter construtivo e reconstrutivo de significações que é a memória, distanciando da compreensão objetiva que a coloca como depósito passivo de fatos, ocorrendo no tempo presente sobre questões do passado.

Por fim, o posicionamento histórico embasa o presente trabalho na medida em que não se busca considerar a História como linear, única e hegemônica, direcionando as análises das narrativas para o heterogêneo, 
plural e múltiplo, enfatizando que as histórias aqui retratadas são sempre algumas entre outras várias possíveis, localizadas em um tempo histórico que influencia a percepção e a construção do trabalho de investigação. Nesse sentido, destaca-se a relação entre História, memória e conhecimento, cujo cerne está na forma em que os sujeitos amparam suas narrativas em fundos de saber específicos de cada realidade e, com isso, produzem novos modos de viver e resistir.

\section{VIOLÊNCIA DE GÊNERO E AS LEMBRANÇAS DE UM FUTURO POSSÍVEL}

“Do rio que tudo arrasta se diz que é violento. Ninguém diz violentas às margens que o cerceiam." - (Bertold Brecht)

A violência contra mulheres pode ser vista no Estado, na mídia, nas instituições, na cultura, na arte, na política, no mercado de trabalho e nas relações familiares (Bandeira, 2014; Saffioti \& Correa, 2001). Possui diferentes dimensões - psicológica, física, sexual, reprodutiva e econômica - e se exerce de diferentes modos, como assédio sexual, estupro, lesões corporais, ameaças, esterilizações forçadas e assassinatos (Teles \& Melo, 2017). Essas múltiplas facetas não estão desassociadas, mas frequentemente se sobrepõem: não é incomum, por exemplo, que a violência econômica seja acompanhada de violência psicológica (Cardoso, 1997; Gregori, 1993).

Toda essa complexidade revela um tipo de opressão enraizada na formação dos sujeitos ao longo da trajetória humana, ainda que transfigurada pelos períodos históricos e regiões geográficas (Lerner, 1986; Mohanty, 1984), resultando em uma dinâmica na qual as mulheres ocupam posições ora de sujeição, ora de resistência ao criar meios inesperados e, por vezes, coletivos, de insubmissão (Narvaz \& Koller, 2006). Nesse sentido, ainda que como pano de fundo, a violência de gênero está sempre presente nas ondas e abordagens de todo o movimento feminista, que, em sua pluralidade, busca remover da normalidade essas situações violentas naturalizadas pelo senso comum (Segato, 2003; Solís \& Pintos, 2002).

No contexto desta pesquisa, deve-se observar que o grupo abordado se baseia no chamado "Feminismo Marxista”, como o próprio nome do movimento que criou a Casa anuncia. Diversas são as estudiosas dessa corrente originária do final do século XIX e que ganhou força no Brasil em torno da década de 1980, com o processo de redemocratização do País (Pedro, Mello, \& Oliveira, 2005). Foi nesse período que políticas públicas nacionais como as delegacias da mulher foram criadas, dando início às redes estaduais de enfrentamento à violência contra mulheres, como a existente em Minas Gerais (Martins, Cerqueira, \& Matos, 2015; Santos \& Izumino, 2005).

Autoras brasileiras como Heleieth Saffioti $(1987,2015)$ e Zuleika Alambert (2004) foram precursoras na construção da vertente marxista influenciada pelos clássicos de Alexandra Kollontai (1977) e Rosa Luxemburgo (2002). Atualmente, nomes expoentes como Angela Davis (2016), Patricia Hill Collins (2017, 2019) e Nancy Fraser (2009) marcam o cenário internacional e buscam explicar a desigualdade de gênero, e consequentemente a violência contra mulheres, a partir da ótica marxiana, apontando a luta de classes como caminho fundamental ao seu combate.

Aprofundando-se na vertente marxista, Saffioti (2015) contesta a ideia de que o liberalismo econômico seria caminho para emancipação feminina pela entrada das mulheres no mercado de trabalho. Pelo contrário, são a força motriz do sistema de produção e acumulação de capital, tendo em vista que o trabalho de reprodução e cuidado dos indivíduos é prestado por elas em todas as esferas da vida, muitas vezes sem qualquer pagamento (Arruzza, Bhattacharya, \& Fraser, 2019). 
Saffioti (1995) destaca que o problema "desconhece qualquer fronteira: de classes sociais, de tipos de cultura, de grau de desenvolvimento econômico, podendo [...] ser praticado em qualquer etapa da vida das mulheres e por parte de estranhos ou parentes/conhecidos, especialmente destes últimos” (p. 8). Pode-se dizer que a violência de gênero está no cerne da constituição do sujeito moderno e, mesmo quando a violência é exercida por mulheres, essas "como categoria social não têm [...] um projeto de dominação-exploração dos homens" (Saffioti \& Corrêa, 2001, p. 116).

Paralelamente, autoras como Carneiro (2001) e Buck-Morss (2017) acrescentam que sem a expropriação das terras de pessoas racializadas, bem como a retirada de sua condição de sujeito pela escravidão, a acumulação econômica dos grandes capitalistas do mundo contemporâneo não seria possível. Em especial, no Brasil, Carneiro (2001) atenta-se ao fato de que "o mito da democracia racial, ao desracializar por meio da apologética da miscigenação" (p. 14), ocultou a desigualdade de raça, fazendo com que as memórias materiais da escravidão jamais parassem de se repetir. Saffioti (1987), na mesma linha, mostra também como "a mulher, o índio, o negro, o mulato, o homossexual, o bissexual constituem contingentes que, por definição, não podem aspirar a posições de mando" (p. 95) e evidencia “o caráter endêmico da violência de gênero" (p. 95).

A despeito dos avanços conquistados, o caráter estrutural da violência de gênero, bem como a resistência das mulheres na história, ainda é ofuscado pelos canais de comunicação, cujo foco normalmente recai sobre os eventos escandalosos de agressão explícita (Solís \& Pintos, 2002). Por essa concepção, a qualquer projeto de futuro é necessário um feminismo que alcance o mundo das mulheres periféricas, negras, pobres, lésbicas, prostitutas, transexuais, gordas, velhas, latino-americanas, africanas, orientais, do sul global, enfim, mulheres dissidentes que não dominam a linguagem hegemônica sobrevalorizada pelas instituições que garantem visibilidade na sociedade. Enfim, como disse D’Alessandro (2017, tradução nossa), desse movimento não dependem apenas as mulheres, mas toda sociedade e natureza, resultando na afirmação de que, "se há futuro, é feminista" (p. 43).

\section{CAMINHOS PERCORRIDOS: MÉTODOS PARA QUÊ(M)?}

"Algumas memórias são presságios" (Lévy \& Robins, 2019).

Visando apresentar as diversas histórias e memórias da experiência da Casa Tina Martins, realizou-se uma observação participante (Serva \& Jaime, 1995) e cinco entrevistas em profundidade (Balasch \& Montenegro, 2003). Além de produzir alguns materiais disponibilizados ao grupo, a participação na Casa proporcionou uma relação mais próxima com as mulheres, integrando ambos os caminhos de aproximação da experiência estudados. A participação ocorreu a partir de abril de 2018, atuando, entre outras maneiras, com a criação de registros fotográficos devolvidos ao grupo e utilizados do decorrer do trabalho de maneira ilustrativa.

Para superar a concepção que relaciona a dimensão política apenas aos sujeitos militantes ou engajados em movimentos sociais, os diferentes grupos da Casa foram abordados: coordenadoras, abrigadas, acolhidas e demais participantes. Entretanto, isso não foi feito sob as mesmas bases. Apesar de a integração entre essas mulheres acontecer de modo livre, algumas abrigadas encontram-se em uma posição de vulnerabilidade e exposição, demandando um cuidado ético. Assim, para não reproduzir o modo patriarcal em que atuam as demais instituições, evitou-se entrevistar diretamente as mulheres nessa situação, valendo-se apenas de falas públicas nas mídias sociais ou em eventos abertos. 
De acordo com Balasch e Montenegro (2003), a produção de narrativas é uma metodologia que emerge na psicologia social crítica, cuja intenção é produzir textos conjuntos entre investigadores e participantes. Isso ocorre em uma determinada "situação para a qual se programa uma série de sessões em que ambos falam e comentam aspectos - previamente consentidos - sobre o fenômeno estudado” (Balasch \& Montenegro, 2003, p. 19, tradução nossa). É válido esclarecer que não houve, nessa etapa, um processo de análise de dados e informações como acontece em muitas perspectivas qualitativas, as quais enxergam a interpretação como possibilidade de desvelar uma realidade oculta por trás do que é dito.

Quanto às formas de atuação na participação decorrente da pesquisa, diversas foram, como: 1) a participação no cotidiano e principais atividades da Casa; 2) participação no núcleo de estudos semanais sobre feminismo e socialismo; 3) registro e edição de eventos, com a produção de possíveis materiais de divulgação do projeto; 4) arrecadação de fundos junto à universidade por meio da submissão de projetos de extensão articulando o trabalho da Casa ao âmbito da extensão universitária; 5) realização de intercâmbios e trocas com o convite às coordenadoras para ambientes da universidade por meio de palestras.

A triangulação das ferramentas de observação participante, dados secundários e entrevistas gerou um vasto material. As entrevistas seguiram o formato de uma conversa e foram integralmente transcritas. Além disso, dois eventos públicos também foram gravados e transcritos a fim de colher falas de outras sujeitas de pesquisa que integram a rede de enfrentamento à violência contra mulher. 0 Quadro 1, que pode ser encontrado após as referências do artigo, mostra como foram realizadas as entrevistas. Nele, estão descritas as pessoas entrevistadas, bem como suas formas de atuação na organização do projeto.

\section{Quadro 1. Materiais registrados: composição do corpus de pesquisa}

\begin{tabular}{l|c|c|c}
\hline Material & Nome Fictício & Área de Atuação & Data \\
\hline Entrevista 1 & Violeta Parra & Comunicação & Jul/2018 \\
\hline Entrevista 2 & Hilda Hilst & Psicologia & Jul/2018 \\
\hline Entrevista 3 & Rosa Luxemburgo & Assistência Social & Jul/2018 \\
\hline Entrevista 4 & Margarida Alves & Abrigamento & Jul/2018 \\
\hline Entrevista 5 & Alexandra Kollontai & Jurídico & Nov/2018 \\
\hline Evento Desconstruções & Pagu & Geral & Nov/2017 \\
\hline \multirow{2}{*}{ Evento “Resiste Tina” } & Alexandra Kollontai & Jurídico & Jun $/ 2018$ \\
\hline
\end{tabular}

Os nomes reais das participantes foram preservados. Para identificá-las, foi solicitado que cada uma indicasse alguma referência do feminismo que a representasse para esse trabalho. Tal procedimento não seguiu nenhum tipo de prescrição metodológica, mas foi empregado de maneira lúdica para ilustrar as conexões entre as memórias e as histórias que circulam na pesquisa. Consideraram-se as narrativas produzidas e as histórias rememoradas como partes de um mesmo processo, o qual possibilitou que as sujeitas percorressem os tempos de suas vidas e novas temporalidade fossem exploradas na pesquisa (Neves, 2010).

Por essa perspectiva epistemológica, toda a pesquisa é vista como uma "narrativa através da qual o pesquisador elabora um texto abrangente dos fenômenos dos quais ele procura dar conta” (Mayorga, 2013, p. 348). 
Indo além de uma análise de dados a partir de uma interpretação objetiva, a pesquisa é dada pela sua participação e escuta dos enunciados na construção de um texto alicerçado em vozes diversas. 0 desafio metodológico se coloca na busca por meios dessa construção sem se submeter ao autoritarismo da interpretação positivista, a qual tende a reduzir os acontecimentos a uma suposta relação de causalidade.

Conforme Foucault (1972), uma possibilidade é o ato de não negar "a inteligibilidade intrínseca dos confrontos" (p. 30), tampouco de evitar "a realidade aleatória e aberta desta inteligibilidade" ao não imputar a tais acontecimentos uma única explicação originária. Foucault (1996) sublinha que não se deve perder de vista que o discurso é sempre um tipo de "violência que fazemos às coisas" (p. 53). Ao tomar essa concepção do saber como base do olhar histórico, a reflexão contínua sobre a inserção do pesquisador no campo de pesquisa torna-se mais importante do que uma lista de procedimentos metodológicos de análise de dados. Assim, cabe ao pesquisador se tomar "como objeto de reflexão contínua" e de reconhecer a si mesmo como "parte da sociedade, e não como sua antítese ou oposição” (Mayorga, 2013, p. 347).

Nas próximas seções, buscou-se organizar essas narrativas expondo alguns momentos e histórias cruciais na apresentação da Casa. Para isso, foram articulados alguns temas principais visando organizar os relatos das mulheres à luz das teorias acerca de história e memória. Os resultados foram organizados em duas seções, começando pelo processo de construção da Casa, com suas disputas políticas e interações com o Estado. Em seguida, foram resgatados alguns relatos sobre a Casa no momento da pesquisa de modo a elucidar os sentidos da experiência e significados presentes no cotidiano do grupo. Para isso, além de ser resgatada parte da trajetória de criação da Casa, também são destacados aspectos presentes na imersão no campo, destacando a construção de novos sentidos como meio de resistência e desnaturalização da violência de gênero.

\section{DA OCUPAÇÃO À CASA: MEMÓRIAS EM MOVIMENTO}

De acordo com Bastos et al. (2017), a omissão do poder público com relação às políticas de moradia tem potencializado no Brasil, sobretudo a partir dos anos 2000, lutas por formas revolucionárias de organização habitacional, como as ocupações urbanas. A ocupação Tina Martins insere-se em um cenário que tem encontrado meios cada vez mais inesperados de mobilização. Margarida, atuante no Movimento Olga Benário desde sua concepção, recorda como surgiu a iniciativa:

A gente tem movimentos parceiros como o Movimento de Luta nos Bairros, Vilas e Favelas (MLB), que é um movimento que luta por moradia, mas que tem na sua predominância mulheres dirigindo esse processo e a gente pensou: "Olha, vamos pegar a experiência desse movimento e vamos organizar uma ocupação de mulheres, específica de mulheres pra tratar das mulheres, pra cuidar de mulheres” (Entrevista - Margarida).

Existe, no entanto, um aspecto que distingue a ocupação Tina Martins das demais ocupações - o que a inseriu em um grupo de movimentos inovadores nas lutas pelo espaço urbano. 0 projeto reivindicava um local para o atendimento de demandas relacionadas ao fortalecimento de pessoas em vulnerabilidade, como o acolhimento de mulheres em situação de risco e a prevenção à violência.

A iniciativa da Casa veio diante da "necessidade de ter equipamentos que pudessem atender as mulheres que precisavam sair do ambiente de violência, pra poder ter condições de se reestruturar, inclusive para ter 
condições de não morrerem" (Entrevista - Margarida). Assim, a ocupação teve sua origem com a entrada de algumas mulheres integrantes do Movimento Olga Benário em um prédio não utilizado por mais de 10 anos na região central de Belo Horizonte, o antigo restaurante da Faculdade de Engenharia da UFMG.

Aprofundando-se no planejamento da ocupação, Pagu relembra situações de violência de gênero que ocorriam nas próprias ações de militância dos grupos parceiros do Movimento Olga Benário. Ela explica que o combate a esse tipo de violência vai além das possibilidades institucionais apresentadas às mulheres, despertando nas integrantes do movimento um interesse na criação de ações que pudessem abarcar toda a experiência de resistência das mulheres.

Isso foi um dos motivos, por exemplo, pelo qual a gente construiu a Tina Martins - que foi um acontecido dentro de uma das ocupações: que foi uma mulher que, toda vez que ela passava por uma situação de violência, ela recorria a nós do movimento e até que chegou uma situação que a gente falou: "Olha, você precisa denunciar”. E aí ela tomou coragem, ela foi denunciar, fez o boletim de ocorrência e quando ela voltou pra casa o companheiro esfaqueou ela e aí ela morreu. Então isso é a realidade que acontece com a grande maioria das mulheres. Elas não têm para onde ir (Fala no Evento Desconstruções/NEOS-UFMG - Pagu).

Em uma retrospectiva das ações de planejamento da ocupação Tina Martins, Pagu, nesse mesmo relato, rememora a "luta de mulheres contra Cunha" em fevereiro de 2016, que, para ela, marcava um cenário de movimentos sociais fortemente polarizado. Nesse contexto de fragmentação das lutas políticas, a pauta da "luta das mulheres pela vida" (e, por conseguinte, contra os crimes de violência doméstica) emergiu como uma possibilidade de unificação das ações de alguns dos movimentos sociais. Nas memórias de Margarida, seria uma ação que fosse um "ponto de convergência para todas essas divergências que existem dentro do seio do movimento feminista que estava discutindo o ato de rua do 8 de março" (Entrevista - Margarida). Nesse momento surgiu a ideia da ocupação, ainda no ano de 2013, com a participação do Movimento Olga Benário na ocupação urbana Eliana Silva, na região do Barreiro, em Belo Horizonte, a qual sediava também algumas partes da organização do movimento Olga Benário.

Na negociação com o governo, o principal argumento contra o movimento era que seria criada uma Casa de Referência da Mulher no futuro em um endereço que até aquele momento era utilizado como estacionamento de uma instituição militar. As integrantes do movimento evidenciaram também não haver nenhum documento que comprovasse o início da construção do abrigo, ou a reversão de fundos em licitação antes de 2017, o que acarretaria uma espera de no mínimo dois anos. Margarida se lembra de que a ocupação não tinha como intuito ser uma Casa de Referência como é atualmente, mas utilizá-la como meio de reivindicação.

A gente achou que inicialmente ia ser uma ocupação meramente reivindicatória, que daí a pouco a polícia ia vir, ia despejar, ia bater nas mulheres, ia ser, enfim, algo que não ia ficar. E a gente percebeu que a gente precisava ficar porque, nas primeiras horas da manhã, mulheres começaram a chegar perguntando o que que era aquilo, que elas precisavam de um lugar daquele para ser atendidas. Então, enquanto a gente estava organizando a ocupação e a gente já começou a fazer trabalho de acolhimento dessas mulheres e começaram a chegar parceiras, advogadas, psicólogas, assistentes sociais, ativistas de diversas naturezas, né? Dentro dessa área dos movimentos sociais para se solidarizar (Entrevista - Margarida).

Por outro lado, as mulheres do movimento Olga Benário, enfatizando a urgência do problema, apontavam dados estatísticos como forma de mostrar a necessidade de um local como a Tina Martins. Rosa mostra clareza 
sobre dados que desvelam o contexto da Rede de Enfrentamento à Violência contra Mulheres em Minas Gerais, os quais apontavam para aproximadamente 300 solicitações por abrigo por dia, enquanto apenas 13 encontravam-se abrigadas em todo o estado. Após diversas fases de negociações, o governo, então, permitiu a utilização de uma casa tombada na região central de Belo Horizonte para sediar por dois anos o projeto.

Atualmente, um consenso entre todas as participantes é o slogan criado por elas. Alexandra, coordenadora do núcleo jurídico, e várias outras participantes assim compreendem a situação: “Acho que a Tina Martins é aquela frase da música que a gente usa que é ‘Com o Estado, contra o Estado e para além do Estado”' (Entrevista - Alexandra). Apesar disso, o sentimento de desamparo é frequentemente presente nas falas das integrantes do movimento, ainda que as próprias integrantes, muitas vezes, se sintam inseridas na Rede Estadual de Enfrentamento à Violência contra Mulher. Rosa mostra como reconhece a rede, entendendo que sua responsabilidade vai além de mediar o conflito do imóvel tombado:

O Estado de Minas que tem 853 municípios, 52 centros de referência de mulher, uma promotoria que atende mulheres vítimas de violência doméstica. Uma promotoria no estado inteiro, pouquíssimas DEAMS [Delegacias Especializadas de Atendimento à Mulher], acho que são 67 DEAMS para o estado inteiro. Então, assim, é uma política que a gente custa, há muito tempo que se fala, que a gente faz lutas para conseguir ampliar os atendimentos, tudo da política de enfrentamento de violência contra mulher.

\section{Figura 1. Feminicídios no Estado}

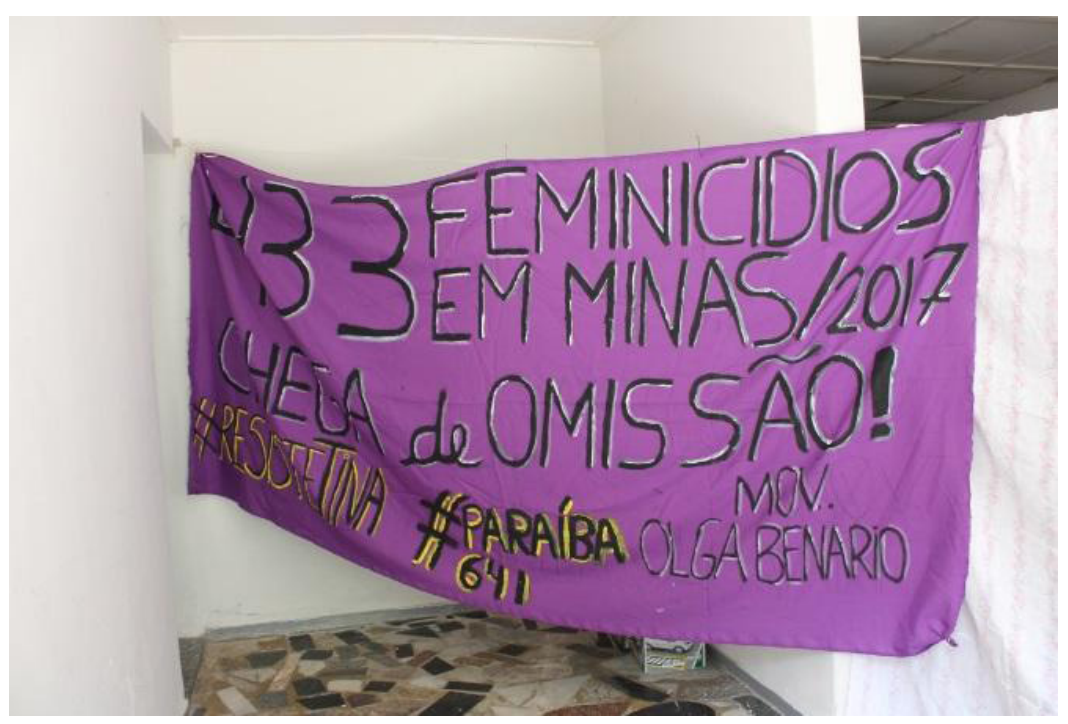

Fonte: Galpão da Casa, fotografia realizada pelos autores.

Margarida relembra que participou das mesas de negociação com representantes do governo e entende que é dever do Estado não apenas ceder o imóvel (recebido em condições insalubres), como também torná-lo habitável e garantir boas condições para a Casa: “A gente fez a ocupação e aí o governo só cedeu o imóvel. Então a gente não tem nenhum tipo de financiamento público investido" (Entrevista - Margarida). 0 processo rememorado converge para uma compreensão histórica e cotidiana das práticas desenvolvidas por sujeitas comuns, conforme Carrieri et al. (2018). Nessa perspectiva, Hilda rememora alguns problemas comuns na rotina da Casa, que esbarram ainda no fato de o imóvel ser tombado: 
Questões hidráulicas que você não pode mandar ninguém consertar. Então, assim, às vezes você vai trocar o chuveiro e aí é a parte elétrica da casa, que não está boa. [...] Tem várias questões físicas que a gente sabe, por ser uma ocupação e por ser aquele imóvel do governo, você não pode fazer porque eu acho que, assim, se tivesse boa vontade, a gente já tinha feito um mutirão, mas você não pode (Entrevista - Hilda).

É fundamental ter essas fronteiras bem delimitadas, uma vez que a relação dessas mulheres com o Estado não ocorre apenas de maneira indireta, mas de modo objetivo, gerando momentos de enfrentamento pessoal. A experiência política da Casa Tina Martins, vista pela ótica das memórias e relatos de suas integrantes, é capaz de demonstrar formas de desnaturalização da violência de gênero pela prática das atividades de luta política. Esse processo se coaduna com as diretrizes de Neves (2010), apresentando como a memória é capaz de revisitar acontecimentos passados, sendo reinterpretados pelos interesses do tempo presente.

\section{PASSADO-PRESENTE NA ORGANIZAÇÃO DE NOVOS SENTIDOS}

Apresentar a organização Casa Tina Martins pela ótica de suas histórias e memórias está longe de ser uma tarefa linear, sendo um processo de reconstrução de narrativas diversas do combate à violência de gênero. Ainda que fosse possível traçar medidas, notas e mapas, por essa ótica, a Casa e seus alicerces se transmutariam em discursos, locais de enunciação, funções, espaços e sentidos, ganhando nova materialização nesse espaço acadêmico. A figura 2, intitulada com a fala de Hilda, mostra a fachada da Casa em diálogo com suas tessituras de crochê que ilustram esse olhar para o presente do momento da pesquisa.

Figura 2.“Esse mundo amplo que é uma Casa de Referência”

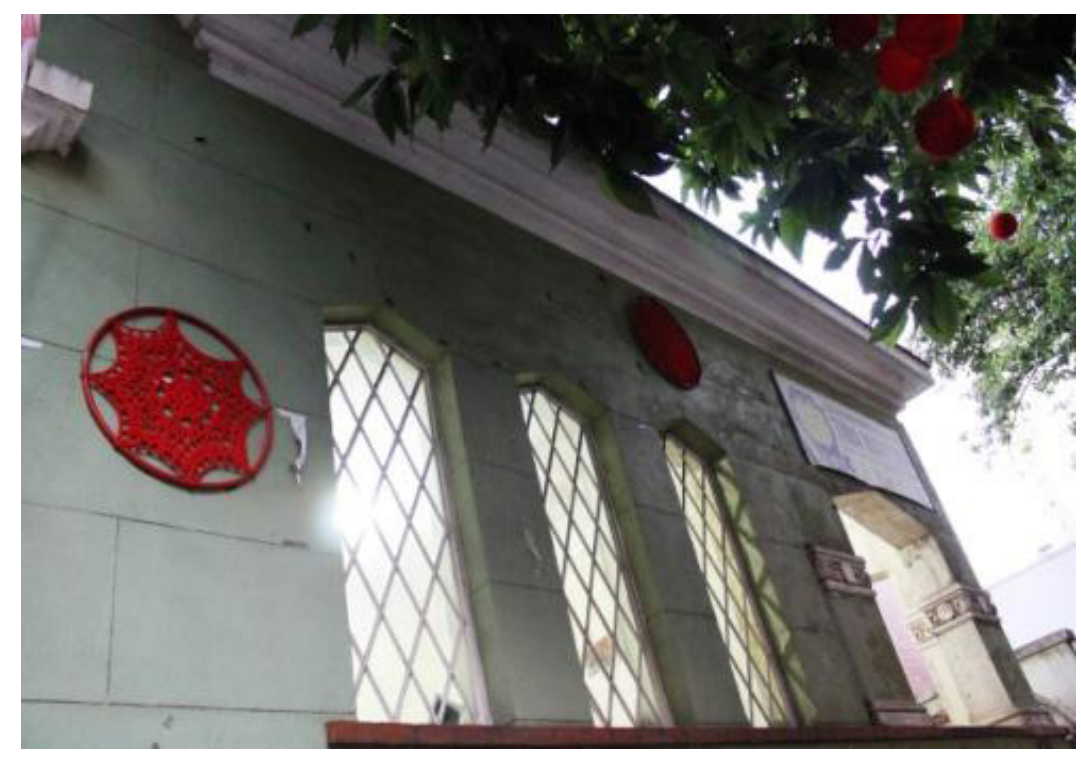

Fonte: Fachada da Casa, fotografia realizada pelos autores. 
O que é uma casa de referência? Recordando a pergunta feita por uma das próprias coordenadoras ao contar seus primeiros passos: “Era uma coisa que eu sempre questionei: é abrigo ou é casa de referência?" (Entrevista - Hilda). 0 termo referência tem a função de apresentar a Casa como um norte adicional a mulheres. Suas integrantes mostram, a partir da vida cotidiana, algumas insuficiências da concepção de casa abrigo como contraponto a uma casa de referência. Rosa explica que o objetivo de ser um espaço de referência se deve principalmente pela priorização no atendimento às questões em longo prazo que visam um horizonte futuro das mulheres. Segundo ela, existe uma reflexão sobre

[...] o que podia se propor pra essas mulheres enquanto perspectiva futura, pra não só tirá-las da violência, mas como para inseri-las novamente na sociedade. Porque muitas das vezes acaba que a violência tira essas mulheres, afunda [elas] ainda mais ali dentro do privado, dentro das casas ou dentro do abrigo (Entrevista - Rosa).

Essa perspectiva se alinha às teorias de Saffioti (1987) acerca do caráter estrutural da violência de gênero, a qual não se reduz a eventos isolados de agressão verbal ou física. É nesse sentido que a necessidade de uma resistência que abarque frentes múltiplas de atuação lança mão de práticas organizacionais como as "escalas de acolhimento", que se referem ao tempo que cada participante se dispõe a ficar na Casa coordenando as outras frentes de atuação.

Ao mesmo tempo em que essa é a maneira como as integrantes se organizam para garantir pelo menos uma pessoa do movimento no espaço, aberto 24 horas por dia, é também uma possibilidade de aprendizagem organizacional que acolhe novas interessadas. Além disso, essa atividade fomenta a criação de laços e alinhamento e promove a consolidação de responsabilidades fundamentais à continuidade do trabalho feito pelo grupo, como relata Alexandra, na fala seguinte:

A gente tem uma visão, uma linha muito certa de como a gente defende essa Casa, de qual tipo de política a gente defende, então é importante que todas nós estejamos coesas. [...] quando você é do Movimento, você entende a política, se envolve mais, tem uma responsabilidade maior porque você entende o que significa, que essa Casa só funciona por conta do Olga, a Casa não é independente. Quando você não tem essa relação com o movimento político, simplesmente um dia você pode acordar e falar: "Ah, não vou, não quero, cansei”, e vai embora. E aí, como é que fica o trabalho? (Entrevista - Alexandra).

As demais funções acontecem paralelamente à escala. Os atendimentos psicológicos, jurídicos ou assistenciais são realizados em uma sala separada, próximo ao espaço administrativo. A organização dos ambientes é planejada de modo que a maioria dos espaços de convivência, como a recepção, a sala de estar e o galpão externo onde ocorrem os eventos voltados ao público, é decorada com fotos que resgatam as mulheres da história e do feminismo, como Bárbara de Alencar e Pagu, bem como com símbolos de ações coletivas contra a violência de gênero, como o movimento latino-americano "Ni una menos" e outras mobilizações feministas. Na Figura 3, é possível observar algumas dessas imagens que fazem referências às mulheres da história, como a própria Espertirina Martins, militante brasileira que deu origem ao nome da Casa. 


\section{Figura 3. Parede do Galpão}

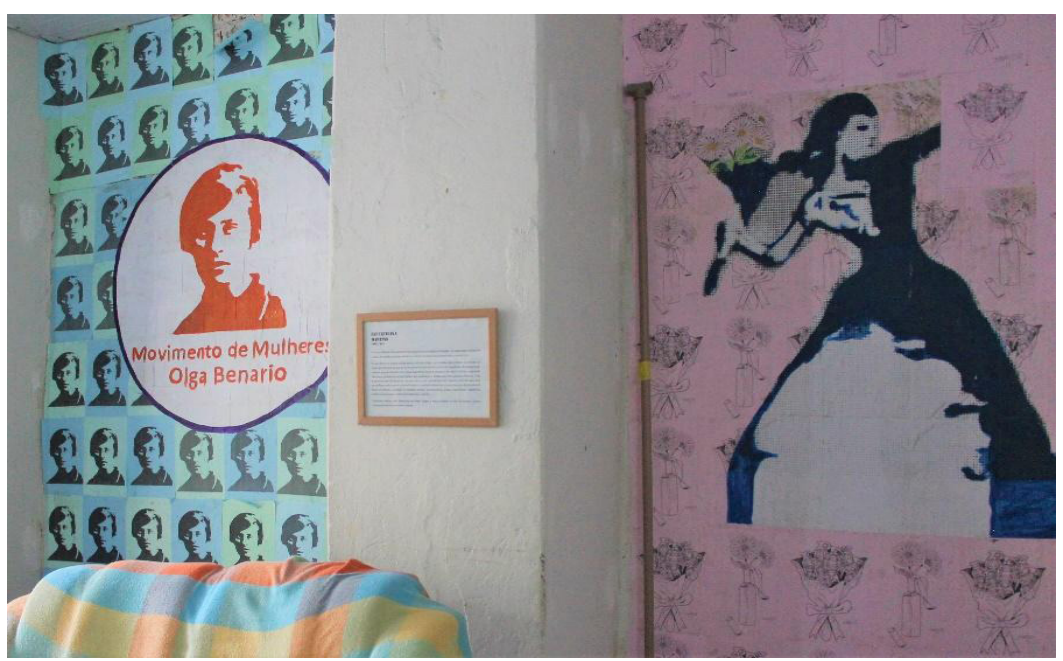

Fonte: Galpão da Casa, fotografia realizada pelos autores.

O grupo se organiza para realizar o acolhimento às mulheres em situação de violência visando atingir mais efetivamente o problema de maneira estrutural. Essa perspectiva perpassa todas as mulheres envolvidas, uma vez que a violência de gênero faz parte da realidade das participantes. Esse tipo de experiência visa ultrapassar os métodos burocráticos normalmente realizados pelas instituições formais. Alexandra relata que o acolhimento é feito a partir de uma escuta que busca "entender o que ela [a mulher] precisa: atendimento psicológico, jurídico... 'Ah, não, ela só precisava passar aqui uma tarde, precisava de uma orientação' [...]” (Entrevista - Alexandra). No dia a dia, o acolhimento é realizado em um campo de possibilidades, nem sempre guiado por uma prescrição, mas pelo respeito ao espaço de cada participante, permitindo uma convivência diária.

Apesar de não haver a intenção analítica de atribuir um sentido oculto por trás desses relatos, seguindo a perspectiva anunciada pela metodologia do artigo, é possível observar a narrativa a partir de suas táticas organizacionais, cujo horizonte é a desnaturalização da violência de gênero. Uma das principais estratégias do grupo refere-se à experiência promovida pela exposição ininterrupta de diferentes vozes e modos de viver no espaço ocupado.

A circulação e convívio de mulheres diversas, pobres, negras, mães, lésbicas, jovens, velhas, brancas, periféricas e centrais, universitárias, em sua maioria usuárias das políticas de cotas, é uma oportunidade singular de ruptura no contexto atual, cujos canais de comunicação promovem os problemas dos grupos dominantes como realidade social universal, conforme Solís e Pintos (2002). Outro aspecto importante acerca da organização da Casa, em consonância com Saffioti (1987) e Fraser (2009), as quais evidenciam o trabalho de reprodução social como imposto às mulheres ao longo da história, bem como Carneiro (2001) e Buck-Mors (2017) assinalam a centralidade da opressão dos povos racializados como fundamento desse mesmo processo, é o fato de que as mulheres negras compõem a maioria das pessoas abrigadas no local.

Por outro lado, as coordenadoras e voluntárias do projeto, em sua maioria mulheres das camadas populares, encontram nesse espaço uma oportunidade única, ao mesmo tempo de acolhimento coletivo e de engajamento social potencialmente transformador. Existe também uma minoria de voluntárias pertencentes às classes sociais 
mais altas, que também expuseram suas recordações de violência pessoal, bem como a consciência de que qualquer combate à violência apenas é possível diante de uma ação que englobe a desigualdade de gênero em sua dimensão estrutural, corroborando o que foi discutido por Saffioti (1987) ao afirmar que a violência de gênero é transversal a toda sociedade.

Ademais, história e memória se encontram pelo resgate das narrativas históricas de mulheres que marcaram a História no Brasil e no mundo das mais diferentes maneiras, como Olga Benário, Rosa Luxemburgo e Marielle Franco, apresentadas pelas recordações do cotidiano, na organização de eventos voltados ao público externo. Paralelamente às demais atividades, como o acolhimento, a organização de feiras, oficinas diversas, clubes de cinema, rodas de conversa, aulas abertas, promovem a rememoração de temas políticos, não muito evidenciados no dia a dia, como democracia, ditadura, imigração, racismo e saúde.

Na Figura 4, pode-se ver um exemplo dessa articulação de sentidos, que é uma exposição do antigo Jornal Lampião da Esquina, uma publicação voltada aos homossexuais que circulou entre 1978 e 1981 vinculada à imprensa alternativa após a abertura política pós-Regime Militar de 1964 (Ferreira, 2012).

Figura 4. Exposição do jornal “Lampião da Esquina”

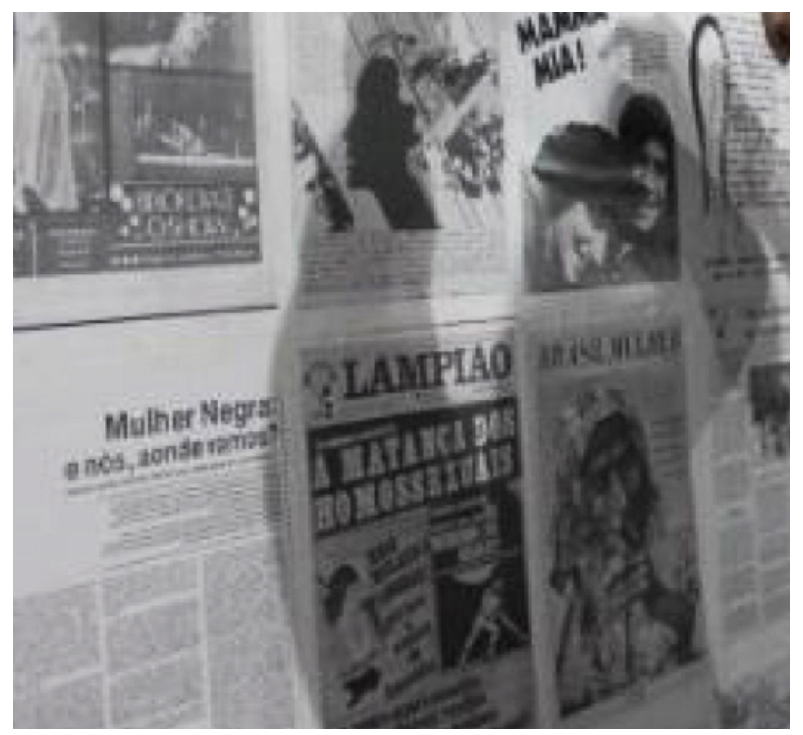

Fonte: Evento Resiste Tina, fotografia realizada pelos autores.

Por fim, a aproximação de uma organização como Casa Tina Martins encontra nas memórias de uma experiência de combate à violência de gênero uma interlocução promissora com o campo da História nos Estudos Organizacionais. A Administração, como área do saber que tradicionalmente se esquivou de sua responsabilização social, ainda que tenha se valido instrumentalmente das ciências humanas como uma de suas principais ferramentas de desenvolvimento organizacional, renegou a discussão de temas centrais do contexto das mulheres na sociedade (Cappelle, Melo, Brito, \& Brito, 2004). Retomar as discussões históricas de sujeitas que, em um primeiro momento, não são protagonistas nos estudos da área se torna fundamental para o avanço rumo a uma gestão histórica e plural (Carrieri \& Correia, 2020). 


\section{CONSIDERAÇÕES FINAIS}

Com este trabalho, estudou-se uma organização cujo sentido é o combate da violência de gênero. Com isso, foi possível integrar aos Estudos Organizacionais tanto a epistemologia da história e memória quanto um breve panorama conceitual sobre gênero. 0 caminho percorrido para isso foi o campo dos estudos de história e memória nos Estudos Organizacionais, tratando, neste caso, de uma organização de combate à violência contra as mulheres, a Casa de Referência da Mulher Tina Martins.

Indo além da concepção institucional de organização como uma entidade fixa, com uma finalidade prática e objetiva, buscou-se lançar luzes a outros sentidos organizacionais, como o de criação de horizontes alternativos por meio da circulação de narrativas históricas de sujeitos dissidentes e, por consequência, de transformação social. Por isso, buscou-se debater, experienciar e assimilar as ações utilizadas pelas sujeitas de pesquisa, intencionando mostrar como essas, ao constantemente resgatarem histórias da luta de mulheres contra a violência, conseguem articular um feminismo que vai além grupo seleto de $1 \%$ das mulheres contempladas por um feminismo teórico ou liberal.

Pelas suas práticas cotidianas em uma organização, as integrantes do grupo encontram a possibilidade de exercer um feminismo crítico, atual e intersecional. Buscou-se, nesse espaço acadêmico, reconstruir esses relatos por meio das memórias recentes levantadas e construídas no decorrer das entrevistas realizadas a partir da observação participante. Esse percurso processual dispensa qualquer tipo de generalização do conhecimento ou de estabelecimento de uma verdade oculta à experiência. Por essa razão, em vez de uma conclusão única, algumas impressões foram construídas em conjunto com as demais integrantes do grupo, como a dificuldade em criar uma relação mais horizontal entre todas as participantes da Casa devido aos desafios da manutenção autônoma do cotidiano e das diferentes necessidades apresentadas na participação de cada grupo: abrigadas, acolhidas, coordenadoras, voluntárias etc.

Vale pontuar também que a participação em um movimento social não significa uma situação de plena emancipação ou liberdade, mas remete à adequação aos outros sistemas de convivência que suscitam a discussão de valores enraizados na cultura e organização da vida. Ainda que indiquem situações de um passado, as memórias apresentas no trabalho atendem aos interesses do tempo presente em que são invocadas, como os desafios colocados por problemas que permanecem no tempo atual da rememoração. É esse quesito que torna a memória rica, pois não é inerte, mas um fenômeno mutável acompanhado de lapsos, esquecimentos, ênfases e realces de acordo com o ritmo da narrativa no momento presente, como bem embasado por Neves (2010).

Para o campo dos Estudos Organizacionais, a pesquisa contribui teoricamente para o avanço de estudos de organizações marginalizadas pelo mainstream da Administração, ressaltando sujeitas por vezes não vistas e silenciadas em uma área do conhecimento que tradicionalmente se dedica a estudar as grandes organizações (empresariais), os grandes sujeitos (de maior poder) e as grandes histórias (sobretudo as de sucesso). Ao mesmo tempo, o campo de história e memória é fomentado com a possibilidade de registro histórico do fazer social por meio da pluralidade, contribuindo para rejeição de histórias que se pretendem únicas e universais a partir do movimento de dar ouvidos aos que são constantemente silenciados. Nesse sentido, não há apenas uma memória, mas diversas, geridas pelos sujeitos e que fazem com que o processo de rememoração seja político, transformador e intencional. Por fim, sugerimos estudos futuros que trabalhem com formas populares de organização pautadas na coletividade, além das memórias de grupos que são ignoradas pelo poder público e permanecem alheias nas discussões protagonistas no campo da gestão. 


\section{REFERÊNCIAS}

Alambert, Z. (2004). A mulher na história, a história da mulher. Brasília, DF: Fundação Astrojildo Pereira.

Arruzza, C., Bhattacharya, T., \& Fraser, N. (2019). Feminismo para os 99\%: Um manifesto. São Paulo, SP: Boitempo Editorial.

Balasch, M., \& Montenegro, M. (2003). Una propuesta metodológica desde la epistemología de los conocimientos situados: Las producciones narrativas. Encuentros en Psicología Social, 1(3), 44-48. Recuperado de: https://cutt.ly/ jIXLoUK

Bandeira, L. M. (2014). Violência de gênero: A construção de um campo teórico e de investigação. Sociedade e Estado, 29(2), 449-469. doi:10.1590/S0102-69922014000200008

Barros, A. N., \& Carrieri, A. P. (2015). O cotidiano e a história: Construindo novos olhares na administração. RAE-Revista de Administração de Empresas, 55(2), 151-161. doi: 10.1590/ So034-759020150205

Bastos, C., Magalhães, F., Miranda, G., Tonucci, J. B., Cruz, M., \& Velloso, R. C. (2017). Entre o espaço abstrato e o espaço diferencial: Ocupações urbanas em Belo Horizonte. Revista Brasileira de Estudos Urbanos e Regionais, 19(2), 251-266. doi: 10.22296/2317-1529.2017V19n2p251

Buck-Morss, S. (2017). Hegel e o Haiti. São Paulo, SP: N-1 Edições.

Cappelle, M. C. A., Melo, M. C. O. L., Brito, M. J. M., \& Brito, M. D. (2004). Uma análise da dinâmica do poder e das relações de gênero no espaço organizacional. RAE-eletrônica, 3(2), 1-17. Recuperado de: https://rae.fgv.br/rae-eletronica/vol3num2-2004/analise-dinamica-poder-relacoes-genero-noespaco-organizacional

Carneiro, S. (2011). Racismo, sexismo e desigualdade no Brasil. São Paulo, SP: Selo Negro, 2011.

Carrieri, A. P., \& Correia, G. F. A. (2020). Estudos organizacionais no Brasil: Construindo acesso ou replicando exclusão? RAERevista de Administração de Empresas, 6o(1), 59-63. doi: 10.1590/S0034-759020200107

Carrieri, A. P., Perdigão, D. A., Martins, P. G., \& Aguiar, A. R. C. (2018). A gestão ordinária e suas práticas: 0 caso da Cafeteria Will Coffee. Revista de Contabilidade e Organizações, 12, 1-13. doi: 10.11606/issn.1982-6486.rco.2018.141359

Clark, P., \& Rowlinson, M. (2004). The treatment of history in organization studies: Towards an 'historic turn'? Business History, 46(3), 331-352. doi: 10.1080/0007679042000219175

Collins, P. H. (2017). Se perdeu na tradução? Feminismo negro, interseccionalidade e política emancipatória. Revista Parágrafo, 5(1), 6-17. Recuperado de: http:// revistaseletronicas.fiamfaam.br/index.php/recicofi/article/ view/559

Collins, P. H. (2019). Pensamento feminista negro: Conhecimento, consciência e a política do empoderamento. São Paulo, SP: Boitempo Editorial.
Coraiola, D., Suddaby, R., \& Foster, W. M. (2017). Mnemonic capabilities: Collective memory as a dynamic capability. RAERevista de Administração de Empresas, 57(3), 258-263. doi: 10.1590/s0034-759020170306

Corrêa, S., \& Kalil, I. (2020). Brasil: ¿La catástrofe perfecta? Projeto Gênero e Política na América Latina. Observatório de Sexualidade e Política (SPW). Rio de Janeiro, RJ. E-Book. ISBN: 978-85-88684-90-4.

Costa, A. S. M., Barros, D. F., \& Martins, P. E. M. (2010). Perspectiva histórica em administração: Novos objetos, novos problemas, novas abordagens. RAE-Revista de Administração de Empresas, 50(3), 288-299. doi: 10.1590/ So034-75902010000300005

Costa, A. S. M., \& Silva, M. A. C. (2019) A pesquisa histórica em administração: Uma proposta para práticas de pesquisas. Revista Administração: Ensino e Pesquisa, 20, 1-20. doi: 10.13058/raep.2019.v2on1.1104

D’Alessandro, M. (2017). Si hay futuro, es feminista. In: Angilletta, F., D'Alessandro, M., \& Mariasch, M. (2017). ¿ El futuro es feminista?. Buenos Aires: Capital Intelectual.

Davis, A. (2016). Mulheres, raça e classe. São Paulo, SP: Boitempo Editorial.

Decker, S., Rowlinson, M., \& Hassard, J. (2020). Rethinking history and memory in organization studies: The case for historiographical reflexivity. Human Relations, o(0o), 1-33. doi: 10.1177/0018726720927443

Ferreira, C. (2012). Imprensa homossexual: Surge o Lampião da Esquina. Revista Alterjor, 1(1), 1-13. Recuperado de https:// www.revistas.usp.br/alterjor/article/view/88195

Foucault, M. (1972). Microfísica do poder. Rio de Janeiro, RJ: Edição Graal.

Foucault, M. (1996). Ordem do discurso. São Paulo, SP: Edições Loyola.

Fraser, N. (2009) O feminismo, o capitalismo e a astúcia da história. Mediações-Revista de Ciências Sociais, 14(2). 11-33. doi: 10.5433/2176-6665.2009v14n2p11

Gabriel, Y., \& Carr, A. (2002). Organizations, management and psychoanalysis: An overview.JournalofManagerialPsychology, 17(5), 348-365. doi: 10.1108/02683940210432600

Gregori, M. F. (1993). As desventuras do vitimismo. Revista Estudos Feministas, 1(1), 143.Recuperado de: https://periodicos.ufsc. br/index.php/ref/article/download/15998/14498

Godfrey, P. C., Hassard, J., O’Connor, E., Rowlinson, M., \& Ruef, M. (2016). What is organizational history? Toward a creative synthesis of history and organization studies. Academy of Management Review, 41(4), 590-608. doi: doi.org/10.5465/ amr.2016.0040

Guarinello, N. L. (2004). História científica, história contemporânea e história cotidiana. Revista Brasileira de História, 24(48), 13-38. doi: 10.1590/S0102-01882004000200002 
Joaquim. N. F., \& Carrieri, A. P. (2018). Construção e desenvolvimento de um projeto de história oral em estudos sobre gestão. Organizações \& Sociedade, 25(85), 303-319. doi: $10.1590 / 1984-9250857$

Kollontai, A. (1977). Selected Writings. Londres: Allison \& Busby.

Lerner, G. (1986). The origin of prostitution in ancient Meso potamia. Signs: Journal of Women in Culture and Society, 11(2), 236-254. doi:10.1086/494218

Lévy, J. L., \& Robins, E. (Prods.). (2019). Atlantique. Belgique, France et Senegal: Les Films du Bal Frakas Productions; Cinekap.

Luxemburgo, R. (2002). Reforma ou revolução (Transcrição de Fernando Araújo). Luxemburg Internet Archive. Recuperado de https://www.marxists.org/portugues/luxemburgo/1900/ ref_rev/index.htm

Maclean, M., Harvey, C., \& Clegg, S. T. (2016) Conceptualizing historical organization studies. Academy of Management Review, 41(4), 609-632. doi: 10.5465/amr.2014.0133

Martins, A. P. A., Cerqueira, D., \& Matos, M. V. M. (2015). A institucionalização das políticas públicas de enfrentamento à violência contra as mulheres no Brasil (nota técnica). Brasília, DF: IPEA.

Mayorga, C. (2013). Pesquisar a juventude e sua relação com a política: Notas metodológicas. Estudos de Psicologia, 18 (2), 343-350. doi: 10.1590/S1413-294X201300020002

Mohanty, C. T. (1984). Under Western eyes: Feminist scholarship and colonial discourses. Boundary, 2, 333-358. doi: 10.1057/ fr.1988.42

Narvaz, M. G., \& Koller, S. H. (2006). Mulheres vítimas de violência doméstica: Compreendendo subjetividades assujeitadas. Psico, 37(1), 7-13. Recuperado de https://revistaseletronicas. pucrs.br/ojs/index.php/revistapsico/article/view/1405

Neves, L. (2010). História oral: Memória, tempo, identidades (2 ${ }^{\mathrm{a}}$ ed.). Belo Horizonte, MG: Autêntica.

Pedro, J. M., de Mello, S. C., \& de Oliveira, V. B. F. (2005). 0 feminismo marxista e o trabalho doméstico: discutindo com Heleieth Saffioti e Zuleika Alambert. História Unisinos, 9(2), 132-138. Recuperado de: http://revistas.unisinos.br/index. $\mathrm{php} / \mathrm{historia/article/view/6419}$

Rowlinson, M., Booth, C., Clark, P., Delahaye, A., \& Procter, S. (2010). Social remembering and organizational memory. Organization Studies, 31(1), 69-87. doi: 10.1177/0170840609347056

Saffioti, H. (1987). O poder do macho. São Paulo, SP: Editora Moderna.
Saffioti, H. (1995). Violência de Gênero: Poder e Impotência. Rio de Janeiro, RJ: Revinder.

Safiotti, H. (2015). Gênero patriarcado violência (2a ed.). São Paulo, SP: Expressão Popular.

Safiotti, H., \& Corrêa, M. (2001). Contribuições feministas para o estudo da violência de gênero. Cadernos Pagu, 16, 115-136. doi: 10.1590/S0104-83332001000100007

Santos, C. M., \& Izumino, W. P. (2005). Violência contra as mulheres e violência de gênero: notas sobre estudos feministas no Brasil. Estudios interdisciplinarios de América Latina y el Caribe, 16(1), 147-163. Recuperado de: http:// www3.tau.ac.il/ojs/index.php/eial/article/view/482

Segato, R. (2003). Las estructuras elementales de la violencia. Bernal, Argentina: Universidad Nacional de Quilmes.

Serva, M., \& Jaime, P., Júnior. (1995). Observação participante e pesquisa em administração: Uma postura antropológica. RAE-Revista de Administração de Empresas, 35(1), 64-79. doi: 10.1590/S0034-75901995000300008

Solís, C. V., \& Pintos, B. M. (2002). Gobernar la violencia: apuntes para un análisis de la rearticulación del patriarcado. Política y Sociedad, 39 (2), 415-435. Recuperado de: https://revistas. ucm.es/index.php/POSO/article/view/POSO0202230415A

Souza, E. M., \& Costa, A. M. (2013). Usos e significados do conhecimento histórico em estudos organizacionais: uma (re) leitura do taylorismo sob a perspectiva do poder disciplinar. Cadernos EBAPE.BR, 11(1), 01-15. doi: 10.1590/S167939512013000100002.

Teles, M. A., \& Melo, M. (2017). O que é violência contra a mulher. São Paulo, SP: Brasiliense.

Velasco, C., Caesar, G., \& Reis, T. (2020, março 5). Mesmo com queda recorde de mortes de mulheres, Brasil tem alta no número de feminicídios em 2019. G1. Recuperado de https:// g1.globo.com/monitor-da-violencia/noticia/2020/03/05/ mesmo-com-queda-recorde-de-mortes-de-mulheres-brasiltem-alta-no-numero-de-feminicidios-em-2019.ghtml

Vizeu, F. (2010). Potencialidades da análise histórica nos estudos organizacionais brasileiros. RAE-Revista de Administração de Empresas, 50(1), 37-47. doi: 10.1590/ So034-75902010000100004

Waiselfisz, J. J. (2015). Mapa da violência: Homicídio de mulheres no Brasil. Brasília, DF: Flacso Brasil.

Wanderley, S., \& Barros, A. (2018). Decoloniality, geopolitics of knowledge and historic turn: Towards a Latin American agenda. Management \& Organizational History, 13, 1-19. doi: $10.1080 / 17449359.2018 .1431551$

\section{CONTRIBUIÇÃO DOS AUTORES}

Todos (as) os (as) autores (as) participaram da conceitualização, abordagem teórica-metodológica, coleta e análise de dados, redação e revisão final do manuscrito. 